\title{
5. Are Neighbourhood Incivilities Associated with Fear of Crime?
}

\author{
Lynne D. Roberts and David Indermaur
}

Beyond the direct harm that crime has on individuals and their communities, crime also has destructive effects indirectly through fear of crime. Whether or not such fear is based on a realistic assessment of the likelihood of crime victimisation, it can have debilitating effects on an individual's physical and mental wellbeing and social functioning. Based on a longitudinal study of persons aged fifty to seventy-five, Stafford, Chandola and Marmot (2007) reported that fear of crime was associated with reduced quality of life, higher rates of depression and poorer mental health. In addition, fear of crime was associated with reduced physical functioning. The authors hypothesised that the poorer mental and physical health outcomes are the result of the curtailment of physical and social activities resulting from the fear of crime. While attempts to estimate the economic and social costs of fear of crime have been limited by the difficulty of measuring intangible costs, Dolan and Peasgood (2007) highlight the need to consider the tangible costs of fear of crime (for example, costs resulting from changed behaviour to reduce the perceived risk of victimisation such as the cost of taking taxis rather than public transport) and associated health costs (in the United Kingdom estimated at £19.5 per year per person).

In addition to the effect on individuals, communities can also be affected where fear of crime is high. Skogan (1986) detailed how fear of crime in 'disintegrating' neighbourhoods can result in residents physically withdrawing from community life and focusing their concerns (and by extension their informal control through surveillance) within the household. This weakening of social organisation and informal social control within the community can provide the opportunity for increased delinquency and disorder, further contributing to physical and social incivilities and neighbourhood decline. This sequential interaction of community disorganisation and incivilities has been the subject of much criminological investigation dating back at least to the seminal work of Skogan and Maxfield (1981) and popularised through the 'broken windows' thesis of Wilson and Kelling (1982). Work in this area continues, including within Australia with key studies including the major National Campaign Against Violence and Crime fear-of-crime research project (Tulloch et al. 1998a, 1998b) and, more recently, McCrea et al.'s (2005) exploration of the relative contribution of the social disorganisation and incivilities of fear of crime within Brisbane. 
Although the corrosive effects of fear of crime have been well documented and are widely accepted, the picture is not as simple as it is often depicted. Recent research has confirmed the doubts some criminologists have had for some time in regard to the construct of fear of crime, questioning the validity of the survey measures frequently used to measure fear of crime (Ditton and Farrall 2007). Further, trying to disentangle the effects of fear from other highly related and co-occurring social dynamics is complex. In this chapter we attempt to tease apart some of these dynamics and look at how fear of crime fits into the social life of Australians drawing on the results of the Australian Survey of Social Attitudes (AuSSA) 2007. ${ }^{1}$

\section{Fear of crime}

There are a number of factors that may contribute to fear of crime. Some research has focused on differences in levels of fear of crime by demographic groupings. The consistent finding in the literature that those who are least likely to be victimised (women and the elderly) experience the greatest fear of crime (see, for example, Brunton-Smith and Sturgis 2011; Ziersch et al. 2007) has been described as 'a central paradox' (Smith and Torstensson 1997, 608) of fear-ofcrime research. Punitive attitudes among the elderly and women point to greater personal and social vulnerability experienced by these groups. Fear of crime is also reflected in greater levels of routine precautions taken by the elderly to protect themselves (Pinkerton James 1992). There may also be interactions between gender and age. One study reported that with increasing age, women increased in their likelihood of feeling safe in the home, but decreased in their likelihood of feeling safe in the neighbourhood (Quine and Morrell 2008b).

Location has also been explored as a source of variation in fear of crime. Quine and Morrell (2008a, 2008b) analysed data from a population survey of older adults (aged sixty-five or older) in New South Wales. The majority of both older men (68.5 per cent) and women (62.6 per cent) reported feeling safe in their home all the time, with a smaller proportion reporting feeling safe in their neighbourhood all the time (men 60.3 per cent, women 52.1 per cent). Older adults in non-metropolitan areas reported feeling safer in their neighbourhood than those living in metropolitan areas, but conversely felt less safe in their homes (Quine and Morrell 2008b). Specifically, older adults living in small rural communities were the most likely to report that they felt safe in their community all of the time (Quine and Morrell 2008a).

\footnotetext{
1 The Australian Institute of Criminology commissioned a range of crime and justice items for inclusion in AuSSA 2007. The analyses reported in this chapter are based on fear-of-crime and incivilities measures that formed part of the range of items commissioned. Please see Roberts and Indermaur (2009) for further details.
} 
Previous criminal victimisation may also affect fear of crime, although data from the British Crime Survey suggest that it is only in areas of high physical and social disorder that previous victims experience higher rates of fear of crime (Box, Hale and Andrews 1988).

Research has also focused on whether fear of crime simply reflects actual crime rates (the 'instrumental hypothesis'). At an aggregate level, people within a neighbourhood largely agree on the degree of disorder within their neighbourhood (McCord et al. 2007), although there is considerable individual variation. Research from the United Kingdom and Canada suggests that somewhere between 8 and 12 per cent of the variance in fear of crime can be directly attributed to differences in neighbourhood context (Brunton-Smith and Sturgis 2011; Fitzgerald 2008). Taken together, these findings suggest that actual crime rates have a relatively modest effect on fear of crime.

Probably the biggest issue to affect the fear-of-crime research is the successful challenge of the underlying concept by a group of British researchers (for example, Ditton and Farrall 2007). What these researchers found was that much of the earlier research was likely to be flawed as it relied on an inadequate methodology of directly asking people about their level of fear of crime. Surveys using this methodology typically result in high levels of fear being reported; however, when respondents are asked how often they felt afraid or what they did as a result of their fear it appeared the 'fear' had only relatively marginal or negligible effects. It now appears likely that earlier methodologies typically employed to measure fear of crime could have produced elevated and artificial readings of the true extent of fear of crime in the population. Briefly, this occurs because when posing simple questions about fear of crime (Are you afraid? How much are you afraid?), there is a strong acquiescence effect: people are likely to respond positively to the suggestion contained in the question that they are, or should be or could be, afraid of crime. This is perhaps not surprising as 'fear' is an appropriate affective response or partner to the concept of 'crime'.

Thus it appears that the alarm over 'fear of crime' appears to have been, at least to some degree, an artefact of the measurement instruments. Although this is likely to be true it remains that the indirect effects of crime-concern about crime, fear of crime and anger about crime - are potent realities in the community and do affect important life choices made by individuals. There is, however, also sufficient doubt about the root causes of this fear, in particular the belief that fear is a simple reflection of overall crime rates (the instrumental hypothesis outlined earlier). There may even be doubt that fear is the result of intermediary variables such as the presence of threatening behaviours such as incivilities. For example, Tyler and Boeckmann (1997) found in their investigation of the deeper causes of punitive-ness that punitive-ness is better explained and understood as the outcome of an experience - a loss of social power and an expression of 
anger about crime. Support for measures such as the 'three strikes and you are out' sentencing legislation introduced in California in 1994 thus is seen as 'expressive' of social power needs rather than a rational response to perceived threats from crime. In this view, looking for a connection between incivilities and fear of crime is useful as incivilities also reflect a loss of certainty or order in the world and should be related to fear of crime, independent of actual crime rates.

\section{Incivilities}

In a nutshell, the incivilities thesis is that 'uncivil' (antisocial, careless and disrespectful) behaviour in the community will directly contribute to the experience of fear of crime. This thesis posits that physical and social disorder in the community, rather than crime itself, lead to increased fear of crime through an emotional response to a loss of social order or certainty (LaGrange, Ferraro and Supancic 1992; Perkins and Taylor 1996; Robinson et al. 2003; Taylor 1999). 'Incivilities' is a term used to describe a range of aspects of the physical environment (such as graffiti, litter, abandoned vehicles) as well as public order problems (such as drug sale and use, violence and drunkenness). Visible signs of neighbourhood disorder are predictive of fear of crime (Brunton-Smith and Sturgis 2011). It should be noted, however, that there are varying conceptions of the incivilities thesis (see Taylor 1999 for a description of five variations of the incivilities thesis). In tracing the development of the incivilities thesis since its inception, Taylor (1999) notes that over time the focus has shifted from the impact of incivilities on the individual to an increased emphasis on ecological processes (for example, Perkins and Taylor 1996) and community change. In this chapter we return the focus to the individual, examining perceptions of incivilities in Australian survey respondents' local area and their relationship to worry about being the victim of a range of crimes.

Previous research has supported the proposed relationship between perceptions of incivilities and fear of crime. Perceptions of incivilities significantly predict fear of crime (Borooah and Carcach 1997; Carcach et al. 1995; Kanan and Pruitt 2002; McCrea et al. 2005; Wyant 2008), perceived risk of victimisation (Kanan and Pruitt 2002; LaGrange, Ferraro and Supancic 1992) and decreased sense of safety (Kanan and Pruitt 2002). Feelings of personal safety are positively associated with perceptions of the neighbourhood as clean and quiet (Ziersch et al. 2007).

There may be significant differences in the proportion of people who feel unsafe in their neighbourhoods according to their perception of incivilities. For example, Fitzgerald (2008) examined fear of crime in Canada based on 
the results of the Canadian 2004 General Social Survey. Approximately onethird (33.8 per cent) of Canadians surveyed who viewed physical disorder as a problem in their neighbourhood felt somewhat or very unsafe from crime in their neighbourhoods compared with only one in seven (14.8 per cent) of those who did not view physical disorder as a problem. Similar results were obtained for perceptions of social disorder as a problem (23.2 per cent versus 13.1 per cent). The effect was even larger if we consider individuals' perceptions of crime in their own neighbourhood compared with other neighbourhoods. Where individuals perceived that their own neighbourhoods had a higher crime rate than other neighbourhoods, almost half (42.2 per cent) of residents experienced fear of crime; however, where respondents believed that their neighbourhood was safer than other neighbourhoods only 15 per cent experienced the same level of fear. Naturally, perceptions of safety and experiences of fear are closely related concepts and it is important not to assume that residents' perceptions are an accurate reflection of the actual level of safety.

Kanan and Pruitt (2002) suggested that perceptions of incivilities reflect social vulnerability and perceived lack of control. Similarly, Jackson (2005) found that perceptions of incivilities affect perceptions of community cohesion, perceived likelihood of crime and the frequency of worry about crime, suggesting the inability of the individual to manage the risk of criminal victimisation and its consequences is one of the reasons individuals worry. Based on qualitative research in neighbourhoods in Adelaide, Palmer et al. (2005) noted how in stigmatised neighbourhoods with high rates of incivilities, fear of crime may restrict social interaction and trust. This relationship may be 'self-reinforcing': perceptions of increasing incivilities increase fear of crime, which in turn reduces social interaction and organisation and further increases incivilities.

Gender may interact with perceived incivilities in influencing fear of crime. As noted earlier, on average, women experience higher levels of fear of crime than men. Females who perceive high incivility in their neighbourhood are almost twice as likely as other females to experience fear of crime. For males, the relationship is even stronger, with males who perceive high rates of incivility in their neighbourhood almost three times as likely to experience fear of crime. That is, while females experience higher overall levels of fear of crime, males' fear of crime is more strongly influenced by perceived incivilities (Carcach et al. 1995).

While there is ample evidence of an association between measures of fear of crime and measures of perceptions of incivilities, it is quite possible, perhaps even likely, that both of these phenomena are the manifestation of sensitivity, concern about crime and/or deeper social factors such as those discussed by Tyler and Boeckmann (1997), including feelings of a loss of social power. 


\section{Measures}

Data for this analysis are drawn from the AuSSA 2007. The two main measures used in this analysis are a measure of incivilities and a measure of fear of crime.

\section{Incivilities}

Incivilities were measured using a five-item scale that asked: 'How would you rate the following problems in your local area?' The content areas were rubbish and litter; graffiti on footpaths and walls; unsupervised groups of young people; people drunk; and people dealing illicit drugs. Each item was measured on a four-point response scale ranging from 'Not a problem at all' to 'A very big problem'. Factor analysis was used to examine the underlying structure of the five incivilities items. These five items form a uni-dimensional scale with good internal reliability (Cronbach's alpha $=0.84$ ). Responses from each item were combined to provide a scale score. Data were recoded so that higher scores on the scale reflected greater problems. Possible scale scores ranged from 5 (the five types of incivilities not a problem at all) to 20 (all five types of incivilities a very big problem).

\section{Fear of crime}

While 'fear of crime' is a term in common public use, it has been conceptualised in a number of ways in the research literature: concern about crime; perceived risk of victimisation; perceived threat; and behavioural responses to fear (Skogan 1999). In this survey, fear of crime was measured using a seven-item scale that asked" 'How worried are you that the following will occur to you?' The content areas were: being physically attacked at home; being physically attacked on the street or other public space; being sexually assaulted; having your home/place of residence broken into; having your identity stolen via the Internet; having your credit card stolen; and having your credit card details used illegally via the Internet. Each item was measured on a four-point response scale ranging from 'Not worried at all' to 'Very worried'.

Factor analysis was used to examine the underlying structure of the fear-ofcrime items. Two underlying components were identified. The first component includes the items on worry about physical attack within the home and on the street, sexual assault and having the home broken into. This component has been labelled Fear of physical crime. The four items were computed into a scale with good internal consistency (Cronbach's alpha $=0.86$ ). The second component includes the remaining three items on worry about having personal identity stolen and credit cards stolen and illegally used on the Internet. This component has been labelled Fear of identity theft-related crime. The three items were computed into a scale with good internal consistency (Cronbach's alpha = 0.88). Data were recoded so that higher scores on the scales reflect higher levels 
of fear of crime. Possible scale scores range from 4 to 16 on the fear of physical crime scale and 3 to 12 on the fear of identity theft-related crime scale. The two fear-of-crime scales are moderately correlated $(\mathrm{r}=0.47, \mathrm{p}<0.001)$. That is, people who scored highly on the fear of physical crime scale were also likely to score highly on the fear of identity theft-related crime scale, while those who scored low on one scale were likely to score low on the other scale.

\section{Results}

\section{Incivilities}

AuSSA 2007 respondents were asked how much of a problem a range of 'incivilities' was in their local area. The results (Table 5.1) indicate that the proportion of Australians nominating incivilities as a problem ranged from 24 per cent (for litter) to 37 per cent (for drug dealing).

Table 5.1 Ratings of Size of Problem of a Range of Incivilities in Local Area (per cent)

\begin{tabular}{lccccc}
\hline Size of problem & Rubbish/litter & Graffiti & $\begin{array}{c}\text { Unsupervised } \\
\text { groups of } \\
\text { young people }\end{array}$ & $\begin{array}{c}\text { Drunk } \\
\text { people }\end{array}$ & $\begin{array}{c}\text { Drug } \\
\text { dealing }\end{array}$ \\
\hline A very big problem & 6.3 & 8.6 & 12.8 & 9.3 & 13.9 \\
A fairly big problem & 17.4 & 20.1 & 23.9 & 18.2 & 23.0 \\
Not a very big problem & 60.6 & 52.9 & 47.2 & 50.6 & 41.0 \\
Not a problem at all & 15.8 & 18.4 & 16.0 & 22.0 & 22.2 \\
Total & 100 & 100 & 100 & 100 & 100 \\
\hline
\end{tabular}

Source: Australian Survey of Social Attitudes 2007.

Response options of 'A very big problem' and 'A fairly big problem' were collapsed into one category ('A big problem') to allow comparisons across types of locations. Approximately four out of 10 survey respondents (41.5 per cent) do not report a big problem with any of the five incivilities in their local area, while 7.1 per cent report a problem across all five types of incivilities.

There are differences in perceptions of incivilities across types of locations (Figure 5.1). With the exception of graffiti, remote-area respondents reported higher rates of incivilities than respondents from capital cities, other metropolitan areas and rural areas. 


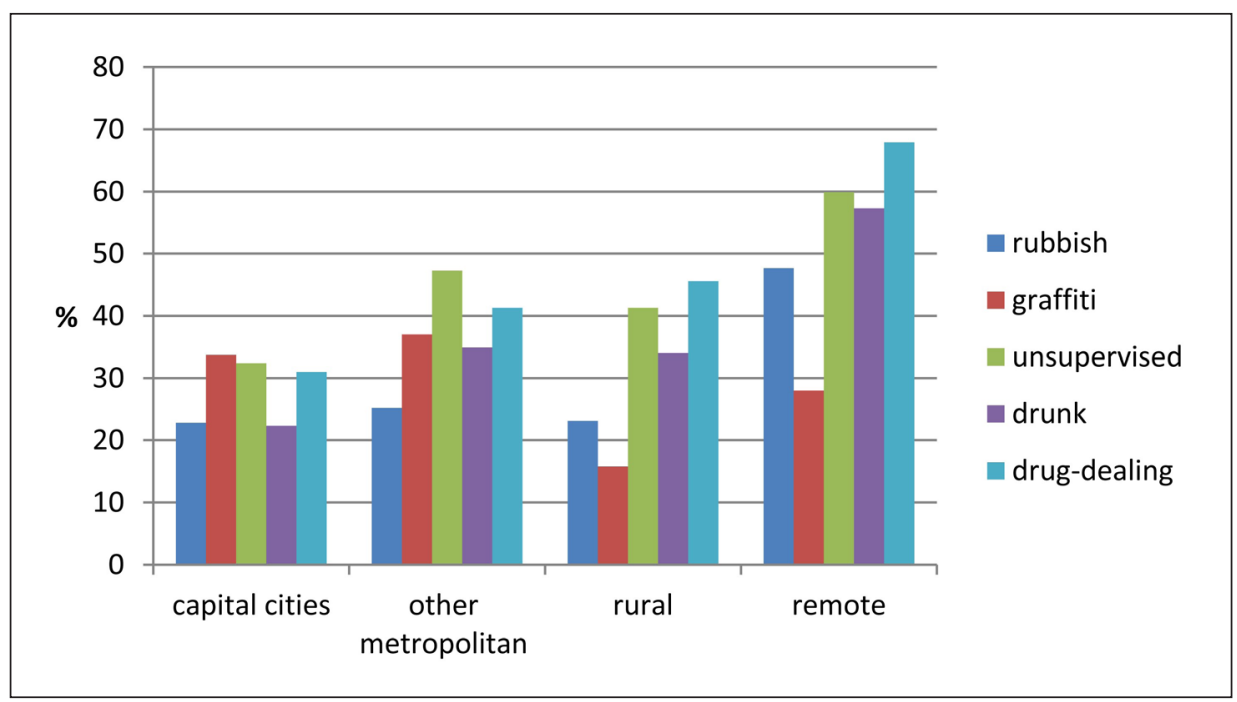

Figure 5.1 Types of Incivilities Rated as a Big Problem by Location (per cent)

Source: Australian Survey of Social Attitudes 2007.

There were no significant differences between males and females in perceptions of incivilities, and only a very weak negative association with age $(\mathrm{r}=-0.06, \mathrm{p}<0.001)$.

\section{Fear of crime}

The same AuSSA 2007 respondents who responded to questions about incivilities were asked how worried they were about being a victim of a range of crimes. The results are presented in Table 5.2 and indicate that the proportion of Australians fairly or very worried about crime varies widely according to the type of crime. While less than one in five (18.5 per cent) is worried about sexual assault, almost half (49.5 per cent) are worried about having their home broken into.

Response options of 'Very worried' and 'Fairly worried' were collapsed into one category to examine differences in worry about being the victim of crime by location. The results are presented in Figure 5.2. A smaller percentage of survey respondents in rural areas was worried about each of the crimes compared with survey respondents from other locations. 
5. Are Neighbourhood Incivilities Associated with Fear of Crime?

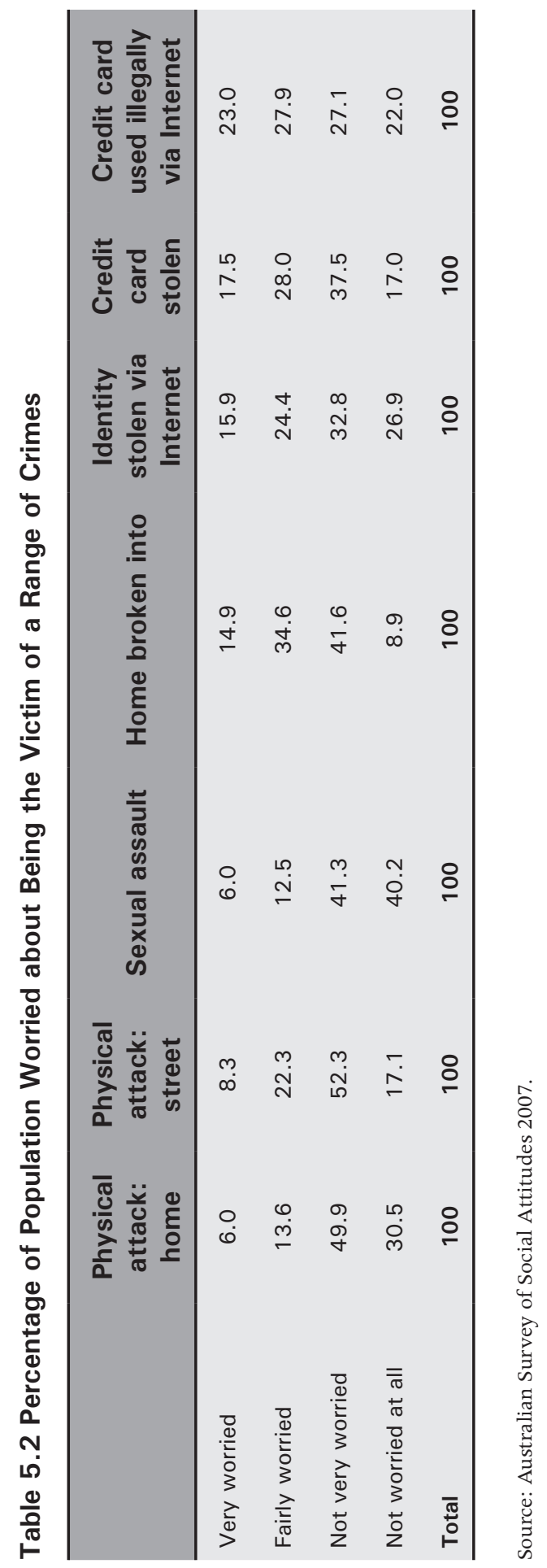




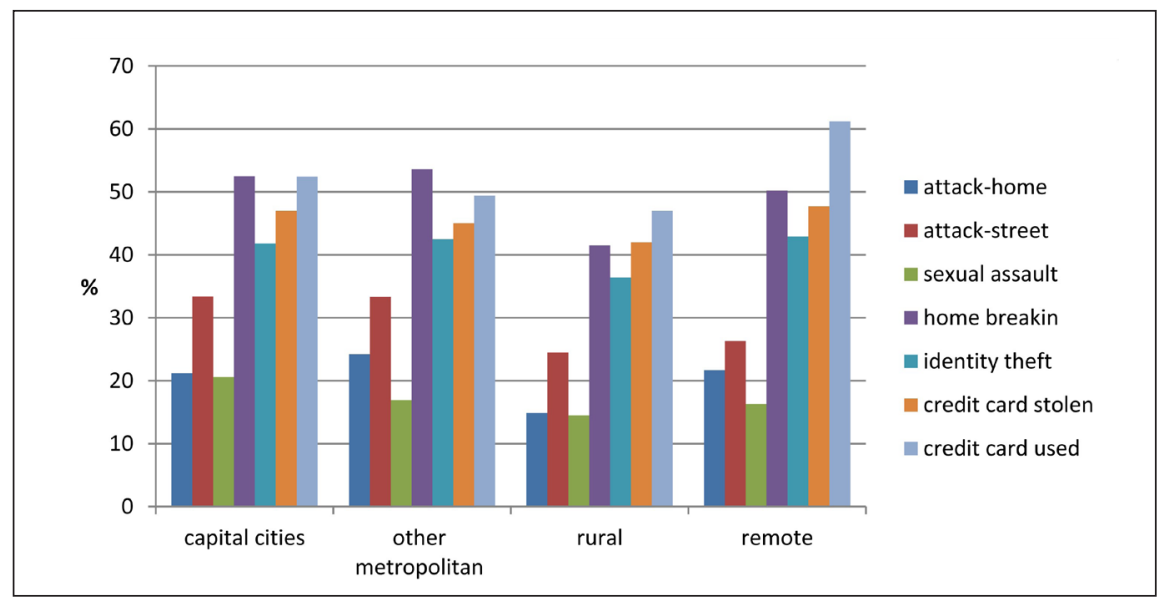

Figure 5.2 Worry about Being a Victim of Various Crimes by Location (per cent)

Source: Australian Survey of Social Attitudes 2007.

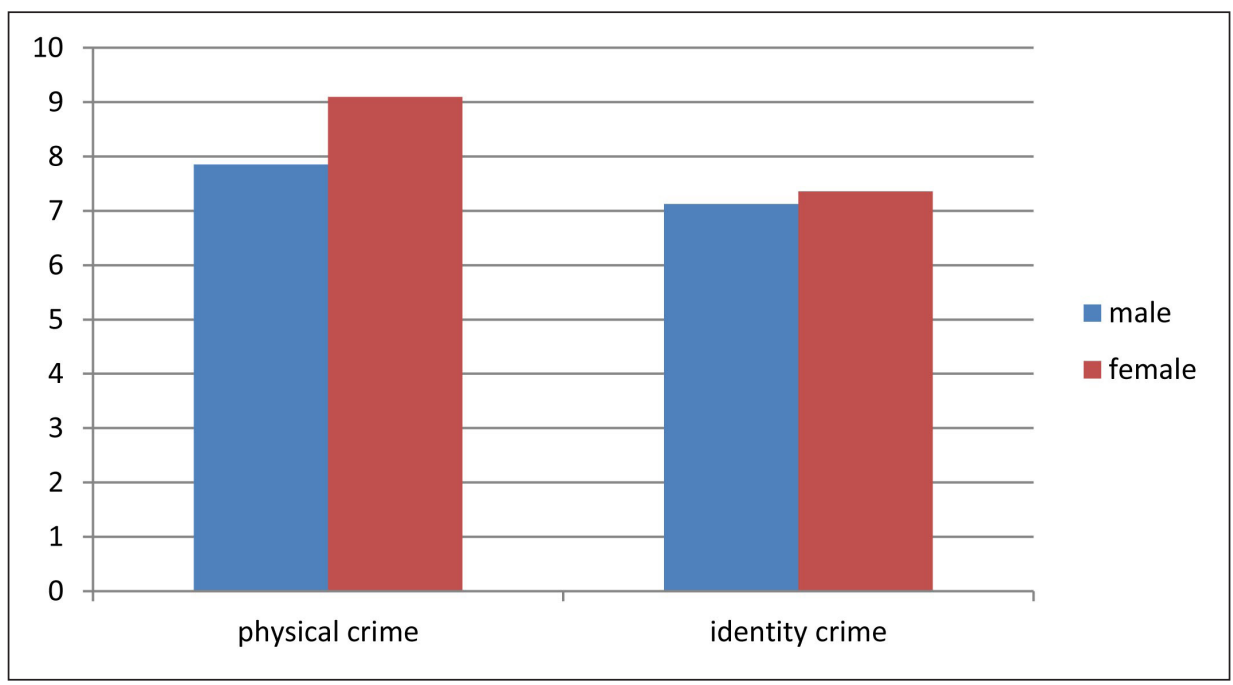

Figure 5.3 Gender Differences in Worry about Being a Victim of Crime

Source: Australian Survey of Social Attitudes 2007.

Total scores for physical crime and identity theft-related crimes were computed. Females scored significantly higher than males on the fear of physical crime $(\mathrm{t}$ [4983.9] $=16.04, \mathrm{p}<0.005)$ and the fear of identity theft-related crime $(\mathrm{t}$ $[4983]=2.82, \mathrm{p}<0.01$ ) scales (see Figure 5.3). Differences in scores between males and females were, however, greater for traditional 'physical crimes' than for identity-related crimes, providing some support for the notion that higher levels of fear of physical crime are due to the perceived greater personal and 
social vulnerability of women to violent crime. Fear of physical crime was not significantly associated with age, with only a very weak significant decrease in fear of identity theft-related crime scores with age $(\mathrm{r}=-0.03, \mathrm{p}<0.05)$, accounting for less than 1 per cent of the variance in scores.

\section{Testing the incivilities hypothesis}

Consistent with the incivilities hypothesis, there was a moderate relationship between perceptions of incivilities and fear of physical crime $(\mathrm{r}=0.38, \mathrm{p}<$ 0.001 ) and a weaker relationship between incivilities and fear of identity theftrelated crime $(\mathrm{r}=0.22, \mathrm{p}<0.001)$. To test whether the impact of perceptions of incivilities on fear of crime was greater for males than females, separate correlations were run for males and females for both fear of physical crime and fear of identity-related theft. The results are presented in Table 5.3. Perceptions of incivilities account for 19 per cent of the variation in males' fear of physical crime, but only 12 per cent of the variation in females' fear of physical crime. Perceptions of incivilities account for 6 per cent of the variation in males' fear of identity theft-related crime, but only 4 per cent of the variation in females' fear of identity theft-related crime. In combination, these results indicate that incivilities have their strongest influence on fear of physical crime, and more so for males than females.

Table 5.3 Correlations between Perceptions of Incivilities and Fear of Crime by Gender

\begin{tabular}{lcc} 
& Physical crime & Identity-related crime \\
\hline Males & 0.44 & 0.25 \\
Females & 0.35 & 0.21 \\
\hline
\end{tabular}

Source: Australian Survey of Social Attitudes 2007.

Further analyses were conducted to examine the unique contribution of gender, age, education, location and perceptions of incivilities to fear of crime. Two multiple regression analyses were used to predict fear of physical crime and fear of identity crime. In the first step of each analysis, the demographic variables of age, gender and years of education were examined. In the second step of each analysis, location (metropolitan versus rural and remote) and perception of incivilities were added to see if they accounted for further variance in fear of crime beyond that of the demographic variables of age, gender and education. The results are presented in Tables 5.4 and 5.5. 
Table 5.4 Unstandardised $(B)$ and Standardised $(\beta)$ Regression Coefficients, and Squared Semi-Partial Correlations $\left(s r^{2}\right)$ for Each Predictor Variable on Each Step of a Hierarchical Multiple Regression Predicting Fear of Physical Crime

\begin{tabular}{clccc}
\hline Variable & & $\boldsymbol{B}$ & $\beta$ & $\boldsymbol{s r}^{2}$ \\
\hline Step 1 & & -0.003 & -0.018 & $<0.001$ \\
& Age & $-0.088^{* *}$ & -0.119 & 0.013 \\
& Education & $-1209^{* *}$ & -0.214 & 0.045 \\
Step 2 & Gender & & & \\
& Age & 0.003 & 0.015 & $<0.001$ \\
& Education & $-0.064^{* *}$ & -0.086 & 0.007 \\
& Gender & $-1.199^{* *}$ & -0.212 & 0.045 \\
& Location & $0.707^{* *}$ & 0.097 & 0.009 \\
& Incivilities & $0.321^{*}$ & 0.382 & 0.143 \\
\hline
\end{tabular}

${ }^{* *} \mathrm{p}<0.001$

Source: Australian Survey of Social Attitudes 2007.

In step one of predicting fear of physical crime, gender and years of education were both significant predictors but age was not. Fear of crime was lower for males than females and decreased with years of education. Together, these variables accounted for 6.2 per cent of the variation in fear of physical crime scores. In step two, location and perceptions of incivilities were both significant predictors and combined accounted for an additional 14.7 per cent of variance in fear of physical crime scores. In total, 20.9 per cent of variance in physical crime scores could be accounted for by the combination of gender, years of education, location and perceptions of incivilities, with perceptions of incivilities and gender being the strongest predictors, accounting for 14.3 per cent and 4.5 per cent unique variance respectively.

Table 5.5 Unstandardised $(B)$ and Standardised $(\beta)$ Regression Coefficients, and Squared Semi-Partial Correlations $\left(s r^{2}\right)$ for Each Predictor Variable on Each Step of a Hierarchical Multiple Regression Predicting Fear of Identity-Related Crime

\begin{tabular}{llccc}
\hline Variable & & $\boldsymbol{B}$ & $\beta$ & $\boldsymbol{s r}^{2}$ \\
\hline Step 1 & & & & \\
& Age & -0.003 & -0.018 & $<0.001$ \\
& Education & -0.002 & -0.003 & $<0.001$ \\
& Gender & $-0.225^{*}$ & -0.04 & 0.002 \\
Step 2 & & & & \\
& Age & 0 & 0.002 & $<0.001$ \\
& Education & 0.017 & 0.023 & $<0.001$ \\
& Gender & $-0.218^{*}$ & -0.039 & 0.002 \\
& Location & $0.426^{* *}$ & 0.06 & 0.003 \\
& Incivilities & $0.19^{* *}$ & 0.23 & 0.052 \\
\hline
\end{tabular}

${ }^{*} \mathrm{p}<0.05$

${ }^{* *} \mathrm{p}<0.001$ 
In step one of predicting fear of identity-related crime, gender was a significant predictor but age and years of education were not. Fear of crime was lower for males than females, but accounted for less than 1 per cent of the variation in fear of identity-related crime scores. In step two, location and perceptions of incivilities were both significant predictors and, combined, accounted for an additional 5.3 per cent of variance in fear of identity-related crime scores. In total, 5.5 per cent of variance in identity-related crime scores could be accounted for by the combination of gender, location and perceptions of incivilities, with perceptions of incivilities being the strongest predictor, accounting for 5.25 per cent of the unique variance.

\section{Discussion}

The AuSSA 2007 provided a vehicle for a national snapshot of fear of crime in Australia. The results indicate that although the majority of Australians are not worried about being the victim of crime there is a significant minority of Australians who report being 'fairly' or 'very' worried. Many more Australians are negatively impacted indirectly through the fear of crime than directly by being the victims of crime. This fear of crime can influence many critical aspects of the individual's functioning and wellbeing, from physical activities to social intercourse and the general erosion of trust (Stafford, Chandola and Marmot et al. 2007). The effect on individuals also ultimately aggregates to a negative effect on communities, which in turn amplifies the deleterious effect further (Skogan 1986).

This survey allows us to compare worry about traditional place-based crime with worry about emerging forms of criminal activity enabled by the rapid development of information and communication technologies, particularly the Internet. An interesting finding from this research is that worry about identity-related crime is now matching, and for some offences exceeding, worry about more traditional place-based crime. The illegal use of credit cards over the Internet was one of the crimes included in this survey that generated the highest levels of worry. Traditional predictors of fear of crime (gender, age, years of education, location) were found to be poor predictors of worry about this new type of crime, and suggest further work is required to develop an understanding of the issues at play here. Future work is required to disentangle worry about identity-related cyber-crime from the actual risk of cyber-crime. For example, Wall (2008a, 2008b) has argued that 'cyberfear' is largely driven by myth perpetuated by the media, and may not be in proportion to the objective reality of cyber-crime.

As predicted, perceptions of incivilities were significantly associated with fear of crime in this research, supporting the incivilities thesis and previous research 
findings (Borooah and Carcach 1997; Carcach et al. 1995; Kanan and Pruitt 2002; LaGrange et al. 1992; McCrea et al. 2005; Perkins and Taylor 1996; Robinson et al. 2003; Taylor 1999; Wyant 2008). Consistent with previous research, gender and perceptions of incivilities were found to interact in predicting fear of crime (Carcach et al. 1995). While females reported higher levels of crime, males' fear of crime was more strongly influenced by perceived incivilities. These findings suggest that reducing perceptions of incivilities may work to reduce fear of crime, particularly for men.

The results of this analysis point once again to the complex interaction between measures of fear of crime and concern about incivilities. Whether these two phenomena are separate manifestations of the same underlying sensitivity about social control or whether they tap qualitatively separate domains remains uncertain; however, the results presented here suggest that the perceptions of incivilities may contribute to, or at least exacerbate, the experience of fear. The most relevant finding of the present study which advances our understanding of the interaction of perception of incivilities and fear is that perceptions of incivilities are associated with both fear of place-based physical crime and nonplace-based identity-related crime. This connection is at a global level, suggesting that general individual dispositional factors are more relevant in understanding fear of crime than reality-based or specific factors, thus further challenging the instrumental hypothesis that fear of crime simply reflects actual crime rates. Because the new Internet-based crimes are not connected with incivilities in the neighbourhood they suggest individual beliefs such as a general loss of trust in all aspects of society and/or the loss of social power are the most relevant factors to look at as contributing to the experience of fear of crime; however, while the perception of incivilities is an important predictor of fear of both placebased physical crime and identity-related crime, perceptions of incivilities have a stronger relationship with fear of physical crime. This suggests that while all three measures may partially tap into an underlying sensitivity about social control, each also measures specific concerns.

One of the methodological implications of the current research is the finding that the acquiescence effect discussed in the introduction as distorting measures of fear of crime may affect the responses of only some research participants. For each of the crimes listed, a proportion of survey respondents (ranging from 17 per cent in relation to having a credit card stolen to 40.2 per cent for sexual assault) answered that they were 'not worried at all'. Further, the varying percentages who were not worried about each of the crimes suggest that this measure is at least partially tapping into concerns about each specific crime rather than a more generalised fear (or absence of fear). This increases our confidence in the use of these types of measures; however, from the questions asked in this study 
it is not possible to assess whether some respondents overestimated their level of fear, and this is an area that requires further research comparing the effects of differently worded questions.

\section{Conclusion}

This chapter has examined the incivilities thesis - the proposition that disorder in the community, rather than crime itself, leads to increased fear of crime through an emotional response of perceived vulnerability - within the Australian context. Our analysis of the Australian Survey of Social Attitudes conducted in 2007 provides some support for the incivilities thesis. Fear of crime increased as perceptions of incivilities in the local area increased. The results have direct policy implications, suggesting that attending to sub-criminal incivilities within neighbourhoods may reduce fear of crime and increase perceptions of safety.

\section{References}

Borooah, Vani K. and Carcach, Carlos A. 1997. 'Crime and fear: evidence from Australia'. British Journal of Criminology 37: 635-57.

Box, Steven, Hale, Chris and Andrews, Glen. 1988. 'Explaining fear of crime'. British Journal of Criminology 28: 340-56.

Brunton-Smith, Ian and Sturgis, Patrick. 2011. 'Do neighbourhoods generate fear of crime? An empirical test using the British Crime Survey'. Criminology 49: 331-69.

Carcach, Carlos, Frampton, Peta, Thomas, Kaye and Cranich, Mathew. 1995. 'Explaining fear of crime in Queensland'. Journal of Quantitative Criminology 11: 271-87.

Ditton, Jason and Farrall, Stephen. 2007. 'The British Crime Survey and fear of crime'. In Surveying Crime in the 21st Century, eds Mike Hough and Max Maxfield. Monsey, NY: Criminal Justice Press.

Dolan, Paul and Peasgood, Tessa. 2007. 'Estimating the economic and social costs of the fear of crime'. British Journal of Criminology 47: 121-32.

Fitzgerald, Robin. 2008. Fear of crime and the neighbourhood context in Canadian cities. Crime and Justice Research Paper Series. Ottawa: Canadian Centre for Justice Statistics. 
Jackson, Jonathan. 2005. 'Validating new measures of the fear of crime'. International Journal of Social Research Methodology 8: 297-315.

Jackson, Jonathan and Gray, Emily. 2010. 'Functional fear and public insecurities about crime'. British Journal of Criminology 50: 1-22.

Kanan, James W. and Pruitt, Matthew V. 2002. 'Modeling fear of crime and perceived victimization risk: the (in)significance of neighborhood integration'. Sociological Inquiry 72: 527-48.

Kelling, George L. and Coles, Catherine M. 1996. Fixing Broken Windows: Restoring order and reducing crime in our communities. New York: Free Press.

LaGrange, Randy L., Ferraro, Kenneth F. and Supancic, Michael F. 1992. 'Perceived risk and fear of crime: role of social and physical incivilities'. Journal of Research in Crime and Delinquency 29: 311-34.

McCord, Eric S., Ratcliffe, Jerry H., Garcia, R. Marie and Taylor, Ralph B. 2007. 'Nonresidential crime attractors and generators elevate perceived neighbourhood crime and incivilities'. Journal of Research in Crime and Delinquency 44: 295-318.

McCrea, Rod, Shyy, Tung-Kai, Western, John and Stimson, Robert J. 2005. 'Fear of crime in Brisbane: individual, social and neighbourhood factors in perspective'. Journal of Sociology 41: 7-27.

Palmer, Catherine, Ziersch, Anna, Arthurson, Kathy and Baum, Fran. 2005. "Danger lurks around every corner": fear of crime and its impact on opportunities for social interaction in stigmatised Australian suburbs'. Urban Policy and Research 23: 393-411.

Perkins, Douglas D. and Taylor, Ralph B. 1996. 'Ecological assessments of community disorder: their relationship to fear of crime and theoretical implications'. American Journal of Community Psychology 24: 63-107.

Pinkerton James, Marianne. 1992. 'The elderly as victims of crime, abuse and neglect'. Trends \& Issues in Crime and Criminal Justice no. 37. Canberra: Australian Institute of Criminology.

Quine, Susan and Morrell, Stephen. 2008a. 'Feeling safe in one's neighbourhood: variation by location among older Australians'. Australian Journal of Rural Health 16: 115-16.

Quine, Susan and Morrell, Stephen. 2008b. 'Perceptions of personal safety among older Australians'. Australasian Journal on Ageing 27: 72-77. 
Roberts, Lynne and Indermaur, David. 2009. What Australians think about crime and justice: results from the 2007 Survey of Social Attitudes. Research and Public Policy Series no. 101. Canberra: Australian Institute of Criminology. <http://www.aic.gov.au/publications/current\%20series/rpp/100-120/ rppl01.aspx>

Robinson, Jennifer B., Lawton, Brian A., Taylor, Ralph B. and Perkins, Douglas D. 2003. 'Multilevel longitudinal impacts of incivilities: fear of crime, expected safety and block satisfaction'. Journal of Quantitative Criminology 19: $237-74$.

Skogan, Wesley. 1986. 'Fear of crime and neighbourhood change in communities and crime'. Crime and Justice: A Review of Research 8: 203-29.

Skogan, Wesley. 1999. 'Measuring what matters: crime, disorder and fear'. In Measuring What Matters, ed. Robert H. Langworthy. Washington, DC: US Department of Justice, National Institute of Justice and Office of Community Oriented Policing Services.

Skogan, Wesley and Maxfield, Max. 1981. Coping with Crime. Beverley Hills, Calif.: Sage.

Smith, William R. and Torstensson, Marie. 1997. 'Gender differences in risk perception and neutralizing fear of crime: toward resolving the paradoxes'. British Journal of Criminology 37: 608-34.

Stafford, Mai, Chandola, Tarani and Marmot, Michael. 2007. 'Association between fear of crime and mental health and physical functioning'. American Journal of Public Health 97: 2076-81.

Taylor, Ralph B. 1999. 'The incivilities thesis: theory, measurement and policy'. In Measuring What Matters, ed. Robert H. Langworthy. Washington, DC: US Department of Justice, National Institute of Justice and Office of Community Oriented Policing Services.

Tulloch, John, Lupton, Deborah, Blood, Warwick, Tulloch, Marian, Jennett, Christine and Enders, Mike. 1998a. Fear of Crime: Audit of the literature and community programs. Volume 1. Sydney: National Campaign Against Violence and Crime.

Tulloch, John, Lupton, Deborah, Blood, Warwick, Tulloch, Marian, Jennett, Christine and Enders, Mike. 1998b. Fear of Crime: The fieldwork research. Volume 2. Sydney: National Campaign Against Violence and Crime. 
Tyler, Tom R. and Boeckmann, Robert J. 1997. 'Three strikes and you are out, but why? The psychology of public support for punishing rule breakers'. Law and Society Review 31: 237-65.

Wall, David S. 2008a. 'Cybercrime and the culture of fear'. Information, Communication and Society 11: 861-84.

Wall, David S. 2008b. 'Cybercrime, media and insecurity: the shaping of public perceptions of cybercrime'. International Review of Law, Computers and Technology 22: 45-63.

Wilson, James Q. and Kelling, George L. 1982. 'The police and neighbourhood safety: broken windows'. The Atlantic Monthly 127: 29-38.

Wyant, Brian R. 2008. 'Multilevel impacts of perceived incivilities and perceptions of crime risk on fear of crime'. Journal of Research in Crime and Delinquency 45: 39-64.

Ziersch, Anna Marie, Putland, Christine, Palmer, Catherine, MacDougall, Colin J. and Baum, Frances E. 2007. 'Neighbourhood life, social capital and perceptions of safety in the western suburbs of Adelaide'. Australian Journal of Social Issues 42: 549-62. 